\title{
Şamanizm: Muğlak Bir Kavramın Anatomisi
}

Araștırma makalesi / Research article

BilaI TOPRAK ${ }^{*}$

Shamanism: Anatomy of an Ambiguous Concept

Citation/C): Toprak, Bilal, (2020). Shamanism: Anatomy of an Ambiguous Concept, Milel ve Nihal, 17 (1), 25-44.

Abstract: The concept of shamanism began to be used in the 1950s to express a larger universe by expanding meaning with the studies of religious scholars such as Mircea Eliade. However, this enlargement, on the one hand, has important traces of its narrow meaning in the past, while pointing to an ambiguous area. In this context, it can be mentioned that the meaning of the concept of shamanism expanded and some problems arising as a result. This study focuses on the semantic change and perception created by the concept of shaman/shamanism, which is very important in terms of the history of religions, anthropology, and archeology.

Keywords: Shamanism, Prehistoric Shaman, Mircea Eliade, Shamanic Religion, Siberia.

* Dr., Mardin Artuklu Üniversitesi, İslami İlimler Fakültesi, Dinler Tarihi Anabilim Dalı [bilaltoprak@artuklu.edu.tr] ORCID: 0000-0001-8039-2128. 
Atıf/C: Toprak, Bilal, (2020). Şamanizm: Muğlak Bir Kavramın Anatomisi, Milel ve Nihal, 17 (1), 25-44.

Öz: Şamanizm kavramı 1950'li yıllarda Mircea Eliade gibi din bilimcilerin çaIışmalarıyla birlikte anlam genişlemesine uğrayarak daha büyük bir evreni ifade etmek üzere kullanılmaya başlanmıştır. Ancak bu genişleme bir yandan geçmişteki dar anlamından önemli izler taşırken bir yandan da muğlak bir alana işaret etmektedir. Bu bağlamda Şamanizm kavramının yaşadığı anlam genişlemesi ve neticesinde ortaya çıkan kimi sorunlardan söz edilebilir. Bu çalışma dinler tarihi, antropoloji ve arkeoloji gibi alanlar açısından son derece önemli olan Şaman/Şamanizm kavramının tarihsel süreç içerisinde yaşadığı anlam değişikliğini ve bunun oluşturduğu algıyı konu edinmektedir.

Anahtar Kelimeler: Şamanizm, Tarihöncesi Şaman, Mircea Eliade, Şamanik Dinler, Sibirya.

\section{Giriş}

Batılı düşünce sisteminin ürettiği kavramların sosyal bilimler üzerinde derin bir etkiye sahip olduğu bilinmektedir. Bu bağlamda din araştırmalarının da söz konusu kavramlar tarafından şekillendiğini söylemek mümkündür. Önceleri oldukça sınırlı bir anlama işaret eden kavramların, daha geniş bir anlamı ifade etmek üzere kullanılmaya başlanması, beraberinde ciddi problemler getirmektedir. Bu dikkat çekici kavramlardan bir tanesi kuşkusuz Şamanizm'dir. Şamanizm, ilk olarak Bering Boğazı'ndan İskandinav sınırına kadar olan geniş bir coğrafyadaki halkların dinlerini ifade etmek üzere kullanılan bir kavram olarak karşımıza çıkmaktadır. Her ne kadar Şamanizm, önceleri Orta ve Kuzey Asya' daki dinî inançları ifade etmek üzere tercih edilmiş olsa da 1950'lerden itibaren Avrupa, Amerika, Afrika ve Avustralya gibi çok farklı coğrafyalarda ve neredeyse dünyanın her yerinde dinsel, büyüsel ve tıbbî uygulamaları ifade etmek üzere kullanılmaktadır. Avcı-toplayıcı veya balıkçı olarak tasvir edilen toplulukların doğa ile kurdukları ilişki modern dönemdekinden oldukça farklıdır. Bu bakış açısı Şamanizm'in ruhlarla ilişkili olduğu sonucuna götürmektedir. Böylece sadece insanların değil, doğadaki her canlı ve cansız varlığın bir ruha sahip olduğu inancı özellikle pozitivizmden bunalan Batılıların ilgisini çekmektedir.

Türkçede Şamanizm ile ilgili yayımlanan akademik çalışmaların çok önemli bir kısmı, Türklerin eski inançları bağlamında konuya yaklaşmaktadır. Dolayısıyla ülkemizde Şamanizm kavramının tarihsel ve din bilimsel arka planının irdelendiği çalışmalara pek 
rastlanmamaktadır. Şamanizm kavramı antropoloji, arkeoloji ve dinler tarihi alanlarında yerli-yersiz kullanılmasına karşın bu kavramın anlam dünyasına dair çalışmaların olmayışı oldukça dikkat çekicidir. Oysa özellikle Batı'da sosyal bilimlerin farklı alanlarında Şamanizm kavramsallaştırmalarına ilişkin tartışmalar değişik zeminlerde sürmektedir.

Şamanizm'in din, sanat ve tedavi/tıp gibi alanların kökeni olduğu iddia edilmiştir. Pozitivizmin ruhsuzluğundan sıkılan bireyler şamanların yöntemlerine ve çevreleriyle olan ilişkilerine ilgi duymuş ve bu durum modern zamanlarda neo-Şamanist akımların ortaya çıkmasına zemin hazırlamıştır. Günümüzde popüler kültürün etkisiyle Avrupa, Amerika ve dünyanın birçok yerinde neo-Şamanist gruplara rastlamak mümkündür. Yeni dini hareketler içerisinde kendisine yer bulan neo-Şamanist akım, bir yandan pozitivizme karşı bir tepki olarak maneviyat arayışlarına cevap verirken bir yandan da ekoloji ve kadın Şamanlar üzerinden feminist hareketlere ilham kaynağı olmuştur. Böylece özellikle Avrupa ve Kuzey Amerika toplumlarında dinin yanında edebiyat, sanat ve müzik gibi alanlarda da Şamanizmin etkisi gündeme gelmiştir. Bu çalışmada, yaklaşık olarak üç asırdır kullanılmasına rağmen özellikle yirminci yüzyılın ortasından itibaren zaman ve mekân mefhumlarını aşan ve geniş bir evreni ifade etmek üzere kullanılan Şamanizm'in anlam dünyasındaki değişiklikler ele alınacaktır.

\section{Sosyal Bilimlerde Şamanizm Kavramının Ortaya Çıkışı}

İlk olarak 17. yüzyılda Rus kaynaklarında karşımıza çıkan Şaman kavramının Tunguz dilindeki "Šaman” kelimesinden türediği düşünülmektedir. Büyücü hekimleri, rahip ve kâhinleri tasvir ve tarif eden bu kelimenin Sanskritçeden geldiği iddia edilse de bu görüş pek kabul görmemiştir. Şaman, ruhlar ve tanrılar ile insanlar arasında bir arabulucudur. O kötü ruhların niyetlerini öğrenir ve çeşitli yollarla insanları korumaya çalışır. Böylece Şaman ruhlarla kurduğu ilişki neticesinde dinî bir işleve sahip olmasının yanında aynı zamanda şifa dağıtan bir sağaltıcı rolünü de üstlenir. Şamanizm'in ortaya çıtığı yer olan Sibirya'da politeizmin ve ruhlara tapınmanın var olduğu bilinmektedir. Burada Şamanizm, söz konusu inançlar- 
dan devraldığ 1 "rahiplik" görevinin yanında şifa ve kehaneti de barındırmaktadır. ${ }^{1}$ Şamanın toplum içindeki rolü farklılıklar göstermekle beraber genellikle büyücü, kâhin, sihirbaz, eczacı, medyum, sorun çözücü ve sağaltıcı olarak belirmektedir.

17. yüzyıldan itibaren Şaman ile tanışan Batılı düşünürlerin bu kavrama yükledikleri anlam oldukça dikkat çekicidir. ${ }^{2}$ Aydınlanma düşüncesinin etkisiyle bu dönemde Sibirya'daki Şamanlar "rahip, büyücü ve doktorların işlevlerini üstlenen sahtekârlar" olarak anlaşılmıştır. Pozitivist ve oryantalist bir yaklaşıma sahip olan Batılı kaşifler Sibirya Şamanları hakkında genellikle olumsuz değerlendirmelere yer vermekteydiler. Buna göre Şamanlar "ilkel" ve "batıl" inançları temsil ediyorlardı. Hatta bunun da ötesinde Şamanlar aslında şeytanın rahipleri konumundayd $1 .{ }^{3}$ Misyoner, tüccar, asker ve benzeri Batılı ziyaretçilerin raporları Avrupa'nın Şamanizm hakkındaki ilk algısının oluşmasında etkili olmuştur. Kuşkusuz bu raporlar abartılı tasvirlerle Batılı okuyucuları büyüleyen, irrasyonel bir yaşam tarzını ve inanç sistemini abartılı tasvirlerle aktarmaktaydı. 18. yüzyılda Avrupalı akademisyenler bu raporlara dayanarak Şamanizm hakkında eserler kaleme almışlardır. ${ }^{4}$ Rusya Bilimler Akademisi' nin ilkini 1733-1743 yılları arasında Sibirya'da yaptığı araştırmalar, Batı'daki Şamanizm ile ilgili çalışmaların ilk akademik dayanağını oluşturmuştur. Ancak hemen belirtilmelidir ki 18. yüzyılda yapılan bu keşifler, aynı zamanda Şamanlar hakkındaki alg1nın oluşmasında ve klişelerin oluşmasında da son derece etkili olmuştur. Çünkü bu eserlerde de Şamanların yetenekli hilebazlar, garip insanlar ve en önemlisi nevrotikler olduğu dile getirilmiştir. ${ }^{5}$

Batı'da Şamanizm kavramı ile ilgili algıların oluşmasında romantizmin de önemli bir etkisi olmuştur. Bilindiği gibi Aydınlanma düşüncesi ile birlikte köken teorileri büyük bir önem kazanmış ve

1 John A. MacCulloch, "Shamanism", Encyclopedia of Religion and Ethics, ed. James Hastings (New York: T.\&T. Clark, 1920), vol. 11, 441.

2 Batılı düşünürlerin Şaman kavramına Rusça kaynaklar vasıtasıyla aşina oldukları genel kabul görmektedir. Ancak Znamenski bunun tam aksini savunmaktadır. Buna göre aslında Ruslar, Alman gezgin ve kâşiflerin eserlerinden veya tercümelerinden hareketle Sibiryalı Şamanlarla tanıştılar. Bk. Andrei Znamenski, The Beauty of the Primitive: Shamanism and Western Imagination (Oxford: Oxford University Press, 2007), 5.

3 Znamenski, The Beauty of the Primitive, 5.

4 Gloria Flaherty, Shamanism and the Eighteenth Century (Princeton: Princeton University Press, 1992), 11.

5 Znamenski, The Beauty of the Primitive, 7. 
bu bağlamda Batı medeniyetinin kökenlerinin nereye dayandığ1 sorusuna cevap aranmıştır. Bu doğrultuda Hint coğrafyası ön plana çıkmış ve burasının Batı'ya kaynaklık ettiği iddia edilmiştir. Şamanizm'in Sanskritçe keşiş "sramana” kelimesinden geldiğini öne süren görüşün temelinde de bu yaklaşım bulunmaktadır. Buna göre Şamanizm Hint coğrafyasında ortaya çıkmış ve daha sonra Kuzey’e doğru yayılmıştır. Linguistik temellendirmeler üzerinden "Şaman" kelimesinin Hint geleneğinden neşet ettiği ve dolayısıyla Budizm ile ilişkili olduğu da ima edilmektedir. ${ }^{6}$ 19. yüzyılda Şamana yönelik temel düşüncenin bu doğrultuda olduğunu söylemek mümkündür. Böylece romantizmin etkisiyle şamanlara yönelik olan ilgi artmış ve seyyahların şamanları tasvirleri görece olumlu bir algının oluşmasını sağlamıştır. Sözgelimi 1820'lerde Sibirya'ya yaptı̆̆ı gezisini aktaran Ferdinand Von Wrangell'e göre, "Gerçek bir Şaman suradan bir hilebaz değil aksine dikkat çekmeyi hak eden psikolojik bir fenomendir". ${ }^{7} \mathrm{Bu}$ durum aslında şamanları şeytanın rahibi olarak gören ve eylemlerini şeytan işi olarak gören yaklaşıma açık bir meydan okumadır. Buna göre şamanların iddia edilenin tam aksine güçlü bir iradeye, zengin bir hayal gücüne ve yaratıcı bir sanat gücüne sahip oldukları dillendirilmiştir. ${ }^{8}$ Pozitivizmin katı yaklaşımlarından bunalan kesimler için Şamanizm ile ilgili romantik anlatılar Avrupa'da büyük bir heyecan meydana getirmiştir.

Romantizmin etkisiyle Şamanizm'e yönelik yazılan eserlerde olumlu bir algı oluşmasına rağmen, Şamanların psişik halleri tartışma konusu olmaya devam etmiştir. Sözgelimi 1920’lerde kaleme alınan ve din araştırmaları açısından önem arz eden Encyclopedia of Religion and Ethics'de Şamanizm maddesinde Şamanlar anormal, nevrotik ve epileptik olarak tanımlanmıştır. ${ }^{9}$ Ancak Şamanların uyuşturucu bağımlısı ve ruhsal bozuklukları olan insanlar olmadıkları ve toplumlarındaki sağlıklı bireyler oldukları da dile getirilmiştir. Bu meyanda Şamanların tedavi yöntemi ile psikanaliz arasında benzerlik olduğunu iddia eden düşünürler de olmuştur.

Gerçekte şamanın tedavisi, psikanalitik tedavinin tam karşılığ1 gibi görünmektedir, şu farkla ki terimler tersyüz edilmiştir. Her iki yöntem de bir deneyim yaratmayı amaçlar ve her

6 Znamenski, The Beauty of the Primitive, 16.

7 Ferdinand Von Wrangell, Narrative of an Expedition to the Polar Sea, ed.: Major Edward Sabine (London: James Madden, 1840), 124.

8 Znamenski, The Beauty of the Primitive, 21.

9 MacCulloch, "Shamanism", 441. 
ikisi de hastanın yaşamak ya da yeniden yaşamak zorunda olduğu bir efsane yaratarak amacına ulaşır. ${ }^{10}$

Şamanın tedavi yöntemi ile psikanalitik tedavi yöntemi arasında benzerlik gören Claude Levi-Strauss, bunu birçok örnekle destekler. Hatta şamanın tedavisinin kimi noktalarda avantajlarını ön plana çıkarır. Ona göre büyücülük uygulamalarının yaygınlaşmasında başarılı tedavilerin önemli bir etkisi bulunmaktadır. ${ }^{11}$ Şamanizm'e yönelik romantizmin etkisiyle açı̆̆a çıkan olumlu tavır İkinci Dünya Savaşından sonra yeni bir ivme kazanmıştır.

\section{Sibirya'dan Küresel Dünyaya Şamanizm'in Yeni Anlam Dünyası}

İkinci Dünya savaşından sonra sosyal bilimlerde ciddi değişimlerin yaşandığı bilinmektedir. Bu bağlamda özellikle 20. yüzyılın ortalarından itibaren Şamanizm alanında da farklı çalışmalar göze çarpmaktadır. Başlangıçta daha çok antropologların, din bilimcilerinin ve Hıristiyan misyonerlerinin ilgi alanına giren Şamanizm 1960'lardan itibaren özellikle Batı toplumunda popüler bir ilgi alanı halini almıştır. Şamanizm'in popülerleşmesinde özellikle iki şahsın etkili olduğu söylenebilir. Bunlardan ilki 1951 yılında yayınladığı Şamanizm: Illksel Esrime Teknikleri ${ }^{12}$ isimli çalışmasıyla akademik alanda Şamanizm'in anlam dünyasını Sibirya'dan tüm dünyaya yayan Mircea Eliade (1907-1986)'dir. Diğeri ise Don Juan'ın Öğretileri ${ }^{13}$ ismini taşıyan seri romanlarıyla ön plana çıkan Carlos Castaneda'dır (1925-1998). Eliade akademik camiada, Castaneda ise yazdiğ 1 deneysel romanlarıyla Şamanizm'in popüler kültür üzerinde etkili olmasını sağlamıştır. Dolayısıyla Şamanizm artık sadece Sibirya coğrafyası ile sınırlı bir kavram olmaktan çıkmış birçok alanla ilişkilendirilmeye başlanmıştır. Böylece Şamanizm, maneviyatçı çevre hareketlerinden feminist yaklaşımlara ve alternatif tıp anlayışlarına varıncaya kadar oldukça geniş bir alanda popüler bir karşılık bulmuştur. Şamanizm'le neredeyse her şeyin ilişkilendirilmeye başlandığı bir süreçte kavramın anlam genişlemesine uğraması temelde iki durumun oluşmasına yol açmıştır. Bu süreçte Şamanizm artık evrensel

10 Claude Levi-Strauss, Yapısal Antropoloji, çev. Adnan Kahiloğulları (Ankara: İmge Kitabevi Yayınları, 2012), 280.

11 Levi-Strauss, Yapısal Antropoloji, 254.

12 Mircea Eliade, Şamanizm: Illkel Esrime Teknikleri, çev.: İsmet Birkan, (Ankara: İmge Kitabevi Yayınları, 2014).

13 Carlos Castaneda, Don Juan'ın Öğretileri, çev.: Nevzat Erkmen (İstanbul: Epsilon Yayınevi, 2009). 
bir dinî tezahür olarak kabul edilirken Şamanın kıyafet ve alet gibi fiziksel yönlerinden ziyade olağanüstü bilinç hallerine dikkat çekilmeye başlanmıştır. ${ }^{14}$

\section{Eliade ve Castaneda'nın Etkisi}

Aydınlanma düşüncesiyle beraber akademide paradigmayı belirleyen pozitivizm ve materyalizm gibi ideolojik yaklaşımlar 1960'larda etkisini yitirmeye başlamıştır. Özellikle İkinci Dünya Savaşından sonra sosyal bilimlerde birey, bilinç ve inanç gibi konulara yönelik ilgi artmıştır. Bu durum sözgelimi, geçmişi anlamanın maddi kültürü yorumlamakla mümkün olabileceğini öne süren "Bilişsel Arkeoloji" yaklaşımının, antropolojide büyük genellemeler içeren teorilerin terk edilmesini ve dinler tarihinde de yeni yöntemlerin ve dolayısıyla yeni kavramların ortaya çıkmasının önünü açmıştır. Yeni paradigmanın gelişmesinde ABD'li düşünürler etkili olmuştur. Bu noktada Eliade ve Castaneda'nın ABD'de bulunan üniversitelerde çalışmaları, diğer yeni dini hareketlerin yanında önemli neo-Şaman merkezlerinin de burada bulunması şaşırtıcı değildir.

Eliade'nin dinler tarihi metodolojisi göz önünde bulundurulduğunda neden dinin tanımlanması ve anlaşılması noktasında Şamanizm kavramını tercih ettiği daha iyi anlaşılacaktır. Dini rasyonel bir zemin üzerinden açıklamanın mümkün olmadığına öne süren Eliade, bu fikrini desteklemek üzere "kutsal", "homo religiosus" ve "Şamanizm" gibi kavramlara başvurmaktadır. 1950'lerden önceki din araştırmalarında geçerli olan paradigma ele alındığında Eliade'nin üstlendiği rol daha iyi anlaşılmaktadır. Eliade, fenomenolojik yöntemle kavramları tarihselliklerinden büyük ölçüde soyutlayarak ele alır. Şamanizm üzerine yaptığı çalışmada da genel anlamda bu yönteme başvurmuştur.

Şamanizm üzerine yapılan bütün araştırmaları bir araya getirmek ve bu karmaşık dinsel olgunun hem morfolojisi hem de tarihi sayılabilecek bir genel tablosunu sunmak, son aşamada, dinler tarihine düşen bir görevdir. ${ }^{15}$

Eliade Şamanizm meselesine yaklaşım tarzını eserinin hemen başında yukarıdaki cümleyle ifade etmektedir. Böylece Şamanizm

\footnotetext{
14 Dieter Eikemeier, "Shamanism", The Brill Dictionray of Religion, ed.: Kocku von Struckrad, (Leiden: Brill, 2006), vol. 4, 1717-1725.

15 Eliade, Şamanizm: Illkel Esrime Teknikleri, 10.
} 
büyük ölçüde tarihsel bağlamından soyutlanarak fenomenolojik boyutta Eliade'nin düşüncesine hizmet etmektedir. Sonunda Şamanizm bir bakıma ana yurdundan koparılarak dünyanın neredeyse her tarafında bulunan doğayla ilişkili inançları açıklamak üzere kullanılan bir kavrama dönüşmüştür.

Eliade'ye göre Şamanlık kurumsal dinlerde rastladığımız "mistik deneyim"in "ilkel" toplumlardaki şekline karşılık gelmektedir. ${ }^{16}$ Batılıları Batılı olmayan kutsal deneyimlerle tanıştırma arzusuyla Eliade, arkaik inançlara ısrarla vurgu yapar. Çünkü Eliade'ye göre Avrupa merkezci bakış açısı ön yargılıdır ve bunu ortadan kaldırmanın yolu dünyanın her yerinde bulunan arkaik insanın dinî tecrübesinin ifşa edilmesinde yatmaktadır. Bu bağlamda Batılılar açısından Batılı olmayan maneviyat öğeleri, Eliade Şamanizm ile ilgili kitabını yayımlamadan önce marjinal etnografik bir ilginin malzemesi durumundayd $1 .{ }^{17}$

Eliade, Şamanizm' in bölgeden bölgeye farklılık gösterdiğini kabul etmekle beraber, temelinde evrensel öğeler barındırdığını öne sürdü. Eğer Şamanizm yerel kültürel öğelerden ve sonradan eklemlenen yeniliklerden arındırılırsa özünde var olan arkaik unsurların ortaya çıkacağını iddia etti. ${ }^{18}$ Bu bağlamda Eliade'nin Şamanizm tanımı oldukça dikkat çekicidir:

Şamanizm arkaik esrime tekniklerinden biridir; hem gizemcilik hem büyü hem de terimin geniş anlamıla 'din'dir. ${ }^{19}$

Eliade, Şamanizmin kendisini de evrensel bir unsur olarak görür ve onu kelimenin geniş anlamıyla din şeklinde tanımlar. Ancak ona göre evrensel unsurlar bundan ibaret değildir. Eliade'nin, Şamanizm'e denk gördüğü esrime de önemli evrensel bir tekniktir. ${ }^{20}$ Bunun yanında göksel dünyaya uçuş (yükseliş) ve yeraltına iniş ${ }^{21}$ ve "Axis Mundi" olarak gördüğü "Evren Ağacı" 22 da birer evrensel öğe olarak belirmektedir. Eliade'nin bir bakıma Şamanizm'i arkaik

16 Mircea Eliade, Mitler, Rüyalar ve Gizemler, çev.: Cem Soydemir, (Ankara: Doğu Batı Yayınları, 2017), 66.

17 Znamenski, The Beauty of the Primitive, 177.

18 Znamenski, The Beauty of the Primitive, 174.

19 Eliade, Şamanizm: Ilkel Esrime Teknikleri, 17.

20 Eliade, Şamanizm: Ilkel Esrime Teknikleri, 25.

21 Eliade, Şamanizm: Ilkel Esrime Teknikleri 73.

22 Eliade, Şamanizm: Illkel Esrime Teknikleri, 597. 
inançları açıklamak ve Batılıları bu tecrübeyle tanıştırmak için anahtar bir kavram olarak kullandığını söylemek mümkündür. Dolayısıyla Eliade, arkaik insanın inanç dünyasını Şamanizm'e indirgeyerek açıklamaktadır.

Şamanizm'in küresel bir kavrama dönüşmesine öncülük eden Eliade'nin çalışmaları, geniş kitlelerle Şamanist geleneği tanıştırmıştır. Carlos Castaneda (1925-1998) ise bir adım öteye giderek onlara Şaman olmayı salık vermiştir. Bir antropolog olan Castaneda, Meksika'da şifalı bitkileri araştırırken Don Juan ile tanıştığını ve 1961-65 yılları arasında ondan şamanlık eğitimi aldığını iddia etmiştir. Böylece Şamanlık Batıda Castaneda'nın kaleminden geniş kitlelere ulaşır. Üstelik Castaneda'nın anlatıları antropologlar üzerinde de bir dönem etkili olur ve Kaliforniya Üniversitesi Antropoloji bölümünün desteğini ve takdirini kazanır. Ancak 1970'lerin ortalarından itibaren eleştirel çalışmalarla Castaneda'nın eserlerinde birçok çelişki tespit edilmiştir. Hatta Richard De Mille, Castaneda'yı içerisinde bazı gerçekler barındırmasına karşın gerçek hikayeler anlatmamakla suçladı ve bu iddialarını yaptığı metin tenkidiyle destekledi. ${ }^{23} \mathrm{Bu}$ bağlamda Don Juan'ın tarihsel bir kişilik mi yoksa hayali bir kurgu mu olduğu bile tartışılmıştır. Ancak tüm bu eleştirilere rağmen Castaneda'nın Şamanizm üzerine yazdı̆̆g romanlar geniş kitlelere ulaşmış ve birçok kesimden okuyucuyu Şamanizm ile tanıştırmiştır.

Şaman ve Şamanizm'in Sibirya'nın dışına çıkarak küresel bir boyut kazanmasında etkili olan Eliade'nin yaklaşımı çeşitli yönlerden eleştirilmiştir. Eliade'ye yönelik en önemli eleştiri, onun hayatında hiçbir şaman görmeden ve ikincil kaynaklara dayanarak Şamanizm'i açıklama çabasına yöneliktir. Bu bağlamda Eliade'nin "masa başı araştırmacısı" olduğu ve araştırmasının önemli olgusal problemler barındırdığı öne sürülmüştür. ${ }^{24}$ Eliade'nin kullandığ́1 malzemenin herhangi bir kritere tabi tutulmadığı ve sistematik bir değerlendirme yapılmadan kullanıldığı iddia edilmiştir. ${ }^{25}$ Eliade'nin Şamanizm ile ilgili düşüncelerini desteklemek üzere

23 Richard De Mille, Castaneda's Journey: The Power and the Allegory (California: Capra Press, 1976), 41.

24 Znamenski, The Beauty of the Primitive, 187.

25 Homayon Sidky, "Ethnographic Perspectives on Differentiating Shamans from other Ritual Intercessors", Asian Ethnolog 69/2 (2010): 221. 
kendi tezini ispatlayacak malzemeyi kullandığ 1 belirtilmiştir. ${ }^{26} \mathrm{Bu}$ bağlamda Michel Perrin, Eliade'nin Şamanizm'i belli belirsiz heterojen özellikler bütününe indirgediğini iddia eder. ${ }^{27}$ Eliade bu bağlamda Şamanist kültürlerin benzerliklerini ortaya koymak için bir bulmacanın eksik öğelerini veya yapbozun eksik parçalarını kurgu ile tamamlar. Sözgelimi Eliade Şamanist uygulamaların yaygınlaşmasını toplumların birbirini etkilemesiyle açıklar. Eliade'ye göre Sibirya'nın güneyindeki kültürler ve antik Yakın Doğu kültürleri, Orta Asya'da ve Sibirya kültürlerini etkilemiş ve tarihöncesi Sibirya'nın Yakın Doğu kültürlerinin derin etkisi altında şekillendiğini vurgulamıştır. Dahası Eliade, bir bakıma Şamanizm'in evrenselliğini ortaya koymak adına Sibirya'nın tarihöncesi olarak adlandırılan dönemden itibaren Mezopotamya, Hint, İran ve hatta Roma'dan derin izler taşıdığını iddia etmiştir. ${ }^{28}$ Ancak Eliade'nin bu yaklaşımını tersine çevirmek de mümkündür. Sibirya inançlarının Yunan, Roma ve Mezopotamya gelenekleri ki etkisi nedir sorusu bu anlamda cevap beklemektedir.

Eliade'ye yöneltilen diğer bir eleştiri ise Şamanizm'i aktarırken Hıristiyan bir perspektiften meseleyi ele aldığı iddiasıdır. Aslında Eliade'nin düşünce sistemini Hıristiyan geleneği üzerinden açıladığı bir bakıma "teoloji" yaptığına dair başka eleştiriler de mevcuttur. ${ }^{29}$ Şamanizm söz konusu olduğunda Eliade, Şamanizm'i açılarken "göksel çıkış/yükseliş" ve yeraltı dünyasına ilişkin Hıristiyan kavramlarıyla Şaman'ın yolculuğunu açıklamaktadır. ${ }^{30} \mathrm{Bu}$ durum Eliade' nin Şamanizm'i Hıristiyan kavramları ve bakış açısından hareketle yorumladığı şeklinde anlaşılmıştır. Her araştırmacı gibi Eliade'nin kişiliği ve yetiştiği ortam çalışmaları üzerinde belirleyici olmuştur. Bu bakımdan Eliade'nin Şamanizm ile ilgili düşüncesinin onun Hıristiyan, roman yazarı ve araştırmacı yönleri göz önünde bulundurulmadan tam olarak anlaşılamayacağı öne sürülmüştür. ${ }^{31}$ Gerçekten de Eliade'nin çalışmasında edebi yönünü özellikle roman

26 Sidky, "Ethnographic Perspectives on Differentiating Shamans from other Ritual Intercessors", 229.

27 Michel Perrin, Şamanizm, çev. Bülent Arıbaş, (İstanbul: İletişim Yayınları, 2014), 24.

28 Eliade, Şamanizm: İlkel Esrime Teknikleri, 607-608.

29 Ramazan Adıbelli, Mircea Eliade ve Din (İstanbul: İz Yayıncılık, 2011), 483.

30 Eliade, Şamanizm: Ilkel Esrime Teknikleri, 592-93.

31 Robert J. Wallis, Shamans/Neo-Shamans: Ecstasies, Alternative Archaeologies and Contemporary Pagans (London: Routledge, 2003), 38. 
yazarlığından kaynaklanan kişiliğinin verdiği avantajla kurgu yeteneği kendisini açıç̧a hissettirmektedir.

Eliade'ye yönelik eleştirilere karşın onun Şamanizm ile ilgili yaklaşımlarını benimseyen ve bu metodoloji doğrultusunda çalı̧̧malarını sürdüren araştırmacılar da bulunmaktadır. Eliadeci isimler arasında en dikkat çeken kişilerin başında gelen Michael Winkelman, Şamanizm'in kültürlerarası bir kavram olduğunu ve sadece Sibirya bölgesi için kullanılmasının doğru olmadığını iddia etmektedir. Ona göre Şamanizm tam da Eliade'nin yaklaşımını doğrular şekilde, bir coğrafyaya özgü bir kavram değil, avcı toplayıcı olarak ifade edilen basit toplumlarda bulunan büyüsel-dinsel uygulamaları ifade etmek üzere kullanılan bir kavramdır. ${ }^{32}$ Nitekim Winkelman gerek kendisinin yaptığ niceliksel araştırma sonuçlarının ve gerekse diğer bazı araştırmaların Eliade'nin Şamanizm'i kültürlerarası bir kavram olarak ortaya koymasının haklılı̆̆ını yansıttığını belirtmektedir. ${ }^{33}$ Eliade'nin Şamanizm ile ilgili yaklaşımının önemli takipçilerinden olan Winkelman'a göre "Şaman" kavramı, tıpkı "mana" ve "tabu" kavramları gibi antropologlar tarafından ödünç alınmış ve ait oldukları kültürlerin ötesinde anlamları karşılamak üzere kullanılmaya başlanmışlardır. Söz konusu örneklerde görüldüğü gibi yerel kavramlardan bir terminolojinin geliştirilmesi kaçnılmazdır.

Eliade Şamanizm'i akademik sahada kültürlerarası bir zemine taşırken Castaneda, Batılıları adeta şamanik bir yolculuğa çıkarmıştır. Dolayısıyla neo-Şamanizm'i 1960'lardan itibaren başlatmak mümkündür. Neo-Şamanizm modern çağda yeni dini hareketlerde ve sanat gibi birçok alanda etkili olmuştur. "Kentsel Şamanizm", "Yeni Şamanizm", "Modern Şamanizm" ve "Çağdaş Şamanizm" gibi adlandırmalar olmasına rağmen neo-Şamanizm isimlendirmesi yaygınlık kazanmışırı. ${ }^{34}$ Şamanizm özellikle Kuzey Amerika'da etkisini göstermiş ve birbirinden farklı alanlarla ilişkilendirilmiştir.

32 Michael Winkelman, “Orijinal Nöroteoloji Olarak Şamanizm”, çev. Ramazan Adibelli, Erciyes Üniversitesi Illahiyat Fakültesi Dergisi 1/20 (2015): 79.

33 Michael Winkleman, "Shamanism and the Origins of Spirituality and Ritual Healing", Journal for the Study of Religion, Nature and Culture 3/4 (2010): 461-462.

34 Wallis, Shamans/Neo-Shamans: Ecstasies, Alternative Archaeologies and Contemporary Pagans, 30. 
Sözgelimi kadın şamanların varlığı ile anaerkillik arasında ilişki kurulmuş ve böylece kadınların daha önce toplumda öncül olduğu gibi çıarımlarda bulunulmuştur. ${ }^{35}$

Şamanizm'in kültürlerarası bir kavrama dönüşmesinden ötürü her ne kadar Eliade "neo-Şamanizm'in babası" olarak görülse de ${ }^{36}$ Michael Harner (1929-2018)'ın etkisi yadsınamaz. Michael Harner 1956 yılında Ekvator'daki And Dağları'nın doğusunda yaşayan Jivaro Kızılderilileri üzerine çalışmaya başlamış devamında Amazon'da yaşayan Canibo Kızılderilileri üzerine saha araştırması yapmıştır. ${ }^{37}$ Batılıları Şamanik gelenek ile tanıştırma isteğiyle Harner, Castaneda'nın Şamanik tecrübe için önerdiği ölümcül derecede tehlikeli entrojen ilaçların kullanımını ve fiziksel/zihinsel zorlu deneyimleri öngören yaklaşımı yerine daha güvenilir ve basit metotlar teklif etmiştir. Ayrıca O 1979 yılında California' da günümüzde hala aktif olan "Foundation for Shamanic Studies"1 kurmuştur. ${ }^{38} \mathrm{Bu}$ kurum dünya çapında arkaik bilgileri organize edip sistematikleştiren ve yayan modern Şamanizm'in ilk okulu olarak kabul edilmektedir. 39

\section{Şamanizm "Tarihöncesi" Toplumların Dini midir?}

Şamanizm'in Batı'da ilgi görmesinin temel nedeni, modern Batı düşüncesinde kendine yer bulamayan irrasyonel olarak ifade edilen bir zeminden kaynaklanmasıdır. Hatırlanacağı gibi katı pozitivizmin etkisiyle şekillenen Batı muhayyilesi çevremizde bulunan canl1cansız her şeyin bir ruha sahip olduğu fikrine karşı şaşkınlık ve hayret duygusu yaşamıştır. Bu bağlamda 19. yüzyıldan itibaren uzun bir dönem etkisini sürdüren Tylor'ın animizm düşüncesi ile Şamanizm arasında da bir ilişki kurulduğunu söylemek mümkündür. Bilindiği gibi Tylor 1871 yılında kaleme aldığı Primitive Culture isimli eserinde "ilkel" insanın çevresinde yaptığı gözlemler neticesinde her şeyin canlılığına ve akıcılığına şahit olduğunu ve böylece ruha

\footnotetext{
35 Eikemeier, "Shamanism", 1723.

36 Daniel Noel, The Soul of Shamanism: Western Fantasies, Imagined Realities (New York: Continuum International Publishing, 1998), 23.

37 Michael Harner, Şaman'ın Yolu, çev.: Meral Bolak (İstanbul: Mia Yayınları, 2006), 29.

38 Wallis, Shamans/Neo-Shamans: Ecstasies, Alternative Archaeologies and Contemporary Pagans, 45.

39 Znamenski, The Beauty of the Primitive, 234.
} 
tapıcılığın ortaya çıktığını iddia etmiştir. ${ }^{40} \mathrm{Hoppal}^{\prime} ı$ da ifade ettiği gibi Tylor ruh anlamina gelen "soul" ve "spirit" kavramları arasında bir ayırıma gitmiştir. Buna göre "soul" insanda bulunurken "spirit" ise diğer varlıklarda yer almaktadır. ${ }^{41}$ Bu bağlamda animizmin Batılı olmayan "küçük" toplumların inanç dünyasını ifade etmek üzere kullanıldığını ve bu hususta Şamanizm'le benzerlik gösterdiğini söylemek mümkündür. Ancak burada animizm ve Şamanizm gibi kavramlar üzerinden "avcı-toplayıcı"ların yapısal ve kalıcı olarak nesneleştirildiklerini söylemek mümkündür. ${ }^{42}$ Fakat gerçekte modern olan/olmayan veya Batılı olan/olmayan toplumlar arasında bir ayırıma gitmenin problemli olduğu anlaşılmaktadır.

Batılı olmayan inançları ifade etmek üzere 19. yüzyıldan itibaren din bilimleri alanında üretilen kavramsallaştırmalar dikkat çekmektedir. Aslında yerel inançlarda mevcut olan kimi kavramların kültürlerarası bir boyut kazandırılarak daha geniş anlamları ifade etmek üzere kullanılması Şamanizm kavramına özgü değildir. Portekiz sömürgesi olan Kongo'dan "Fetiş", Melanezya'dan "Mana", Polinezya'dan "Tabu" ve Kuzey Amerika'daki Ojibwe'den "Totem" gibi kavramlar da benzer şekilde lokal anlamlarının ötesinde geniş bir evreni ifade etmek üzere kullanılmışlardır. Ancak 1920'lerden itibaren indirgemeci sosyal evrim anlayışının terk edilmesiyle beraber söz konusu kavramlar eleştirel bir perspektifle ele alınmaya başlamıştır. Böylece bilim insanları evrensel bir anlamı belirtmek üzere yerel kültürlerin kavramlarını kullanmanın meydana getirdiği sorunlara dikkat çekmeye başladılar. ${ }^{43}$ Bu bakımdan söz gelimi LeviStrauss, "totemizm" kavramının tıpkı diğer 19. yüzyıl kavramlarından olan "ilkel" kavramı gibi bir histeri sonucu ortaya çıktığını öne sürer. Ona göre bu husus, Batılı araştırmacıların kendi evrenlerini

40 Edward Burnett Tylor, Primitive Culture: Researches into the Development of Mythology, Philosophy, Religion, Language, Art, and Custom (London: Murray, 1903), 425-26.

41 Mihaly Hoppal ve Gürbüz Erginer (Çev.), "Sibirya Şamanizminde Doğa Tapınımı", Ankara Üniversitesi Dil ve Tarih-Coğrafya Fakültesi Dergisi 41/1-2 (2017): 209.

42 Martin Porr ve Hannah Rachel Bell, "'Rock-art', 'Animism' and Two-way Thinking: Towards a Complementary Epistemology in the Understanding of Material Culture and 'Rock-art' of Hunting and Gathering People", Journal of Archaeological Method and Theory 19/1 (2012): 173.

43 Lars Kirkhusmo Pharo, "A Methodology for a Deconstruction and Reconstruction of the Concepts 'Shaman' and 'Shamanism'”, Numen 58/1 (2011): 14. 
korumak adına, kendisi dışında bir yere konumlandırdığı insanı tanımlama çabasının ürünüdür. ${ }^{44}$ Diğer bir ifadeyle din araştırmalarında Batı'yı merkeze alan ve ötekini kendisi üzerinden tanımlayan ve değerlendiren bir zihin dünyasının ürettiği kavramların etkin olduğunu söylemek mümkündür.

19. yüzyıldan devraldığımız kavramlar bu anlamda büyük ölçüde sorunlu görünmektedir. Henüz bilim alanlarının tam olarak ayrışmadığı dönemden devraldığımız kavramlar üzerinden oluşan dinler tarihi terminolojisinin birçok kavramı bu bakımdan belirsiz ve karmaşıktır. Çoğu zaman gezginler tarafından önerilen kavramlar antropologlar tarafından sorgulanmaksızın kabul edildi. Etnograf Van Gennep söz konusu belirsiz kavramlar arasında en tehlikeli olanlarından birinin Şamanizm olduğunu belirtmektedir. ${ }^{45}$ Böylece "Şaman/izm" kavramı bir Batı kültür kategorisi olarak karşımıza çakmaktadır. Diğer bir ifadeyle "Şamanizm" her ne kadar yerel bir kavram olsa da Batılı yaklaşımı yansıtan bir kavram olarak belirmektedir. Yaşanan anlam karışıklıklarının önüne geçmek için araştırmacıların çalıştıkları kültürün diline ait kavramları kullanmaları büyük önem arz etmektedir. Dinler arasındaki fenomenlerin benzerliği aradaki farklılığı ortadan kaldırmamalıdır. Özellikle dinler tarihi, antropoloji ve arkeoloji açısından "ilkel" olarak nitelendirilen kültürlerde Şaman kavramı, dini ayinleri yöneten ve şifa dağıtan kahinleri ifade etmek üzere kullanılmaktadır. Bu bağlamda Şamanizm'in "avcı-toplayıcı" olarak ifade edilen göçebe kültürlere özgü olduğu düşünülmektedir. "Tarihöncesi" olarak adlandırılan toplumlar açısından "basit" toplumlarda din adamları "şaman" kavramıla daha hiyerarşik olarak organize olmuş topluluklardaki din adamı ise "rahip" olarak adlandırılmıştır. ${ }^{46}$ Kuşkusuz bu durum dini toplumsal sınıf ve hiyerarşi açısından ele alan bir yaklaşımın ürünüdür. Hatta bir adım ileriye geçerek bu yaklaşımın temelinde din evrimi fikrinin yer aldığını söylemek mümkündür.

44 Claude Levi-Strauss, Günümüzde Totemizm, çev. Kasım Akbaş (İstanbul: Nora Yayınları, 2018), 9.

45 Van Gennep'ten aktaran Pharo, "A Methodology for a Deconstruction and Reconstruction of the Concepts 'Shaman' and 'Shamanism'”, 8.

46 Pharo, "A Methodology for a Deconstruction and Reconstruction of the Concepts 'Shaman' and 'Shamanism'”, 15-18. 
Şamanizm kavramı, Aydınlanma düşüncesinin etkisiyle rasyonel düşüncenin dışında kalan alana ait bir kavramsallaştırmadır. Bilim yerine insanın karizmatik yönünün ve duygularının yaşama egemen olduğu irrasyonel alana yönelik bir tanımlamadır. Böylece Şaman Batılı olmayan basit toplumları hilebaz yöntemlerle kontrol eden bir tiyatro sanatçısı olarak karakterize edilmiştir. ${ }^{47}$ Burada dikkat çekici husus Hıristiyanlık karşısında konumlanan Modern öncesi "ilkel" inançların, bir kavramla açıklanma isteğidir. Söz gelimi Hıristiyanlık ile karşılaştırılabilmesi için, oldukça karmaşık görünen "ilkel" inançların basit bir birliğe indirgenmesi ihtiyacı hissedilmektedir. ${ }^{48}$ Ancak ilginç bir şekilde anlam genişlemesine uğrayan Şamanizm sadece "ilkel" dinin kökeni olarak değil günümüzdeki kurumsal dinlerin de kökenini açıklayacak bir kavram olarak düşünülmüştür. Diğer bir deyişle Şamanizm geleneksel dinlerin en temel yönlerinden biri olarak takdim edilmektedir. ${ }^{49}$ Bu bağlamda Hıristiyanlık geleneğini Şamanizm üzerinden ele alan görüşlere rastlamak mümkündür. Bu tür metinlerde İsa Mesih bir "Şaman" olarak karşımıza çıkmaktadır. ${ }^{50}$ Dolayısıyla Şamanizm hem "tarihöncesi" olarak adlandırılan dönem inançlarını hem günümüzdeki "avcı-toplayıcı" dinlerini ve hem de kurumsal dini geleneklerini açılayabilecek bir kavram olarak önerilmektedir. Kuşkusuz Şamanizm kavramının tüm bu alanları kapsama yeteneğine sahip olması mümkün değildir. Bu durum kavramın bulanık, karmaşık ve anlaşılmaz yapısını perçinlemektedir.

Dinin kökenine yönelik öne sürülen teorilerle birlikte düşünüldüğünde kültürlerarası bir kavrama dönüşen Şamanizm, yazılı kayıtlara sahip olmadığımız "tarihöncesi" dönem için de kullanılmaya başlanmıştır. ${ }^{51}$ Özellikle kaya resimleri ile Şamanlar arasında bir ilişki kurulmuş ve Şamanizm'in dinin ilk şeklini yansıttığını iddia eden yaklaşımlar ileri sürülmüştür. Mitoloji ile ilgili eserleriyle ön

47 Michael Winkelman, "Shamanism in Cross-Cultural Perspective", International Journal of Transpersonal Studies 31/2 (2012), 48.

48 Thomas DuBois, "Contemporary Research on Shamanism", Numen 58 (2011), 111.

49 Brian Hayden, Shamans, Sorcerers, and Saints: A Prehistory of Religion (Washington: Smithsonian Books, 2003), 87.

50 Bradford Keeney, Shamanic Christianity: The Direct Experience of Mystical Communion (Vermont: Destiny Books, 2006), 1.

51 Eikemeier, "Shamanism", 1720. 
palana çıkan Joseph Campbell bile "dinin Şaman'ın gördüğü hayallerin bazılarını ritüele dönüştürmesi neticesinde ortaya çıktığını" iddia etmektedir. ${ }^{52}$ Bu bağlamda kendilerini uzak geçmiş ile ilişkilendiren neo-Şamanist grupların ve Druidler'in Stonehenge ve Avebury gibi kimi Neolitik merkezleri, ritüel amaçlı ziyaret ettikleri bilinmektedir..$^{53}$ Ancak son dönemde yapılan araştırmalar kaya resimleriyle Şamanlar arasında kurulan ilişkinin problemli olduğunu ortaya koymaktadır. ${ }^{54}$ Dolayısıyla dinler tarihi ve antropolojinin yanında arkeolojideki temel kavramlardan biri olan Şamanizm bilinmeyen, anlaşılamayan doğayla ilişkili durumları ifade etmek üzere kullanılmaktadır. Diğer bir ifadeyle arkeolojide günlük hayatla ilişkilendirilemeyen "tuhaf" veriler genellikle ritüel ve Şaman/Şamanistik/Şamanik gibi nitelemelerle açıklanmaya çalışılmaktadır. Ancak bu çabanın anlamadan ziyade muğlaklığa hizmet ettiği aşikârdır.

\section{Bir Kategori Olarak “Şamanik Din” Tanımlaması}

Günümüzde yaygin olan kurumsal dinî gelenekleri "Dünya dinleri” şeklinde, bölgesel ve daha çok modern öncesi "basit, avc1-toplayıc1, ilkel" inançları ise "şamanik/şamanistik" olarak kategorize etmek yaygın bir anlayış olarak belirmektedir. Şamanizm'e yerel din kategorileri içerisinde yer veren Pier Vitebsky'ın "bu isim dünyadaki yüzlerce ve belki de binlerce dine isim olarak verilmektedir" ifadesi Şamanizm kavramının muğlaklığını ortaya koymaktadır. ${ }^{55}$ Ancak bu tasnif ve adlandırma bazı açılardan problemli görünmektedir. Çünkü Şamanizm bir kültürü veya dinî sistemi bütünüyle değil, yalnızca bir yönünü ifade edebilir. ${ }^{56}$ Aksi halde Şamanizm'i üst bir şemsiye gibi düşünmek söz konusu edilen inançların bir kısmının yok sayılması veya görmezden gelinmesi anlamına gelmektedir ki

52 Joseph Campbell, Bill Moyers Joseph Campbell, Mitolojinin Gücü, çev. Zeynep Yaman (İstanbul: Media Cat, 2013), 135.

53 Pharo, "A Methodology for a Deconstruction and Reconstruction of the Concepts 'Shaman' and 'Shamanism'", 14.

54 Peter Bahn, "Save the Last Trance for Me: An Assessment of the Misuse of Shamanism in Rock Art Studies", The Concept of Shamanism: Uses and Abuses, ed. Henri-Paul Francfort (Budapest: Akadémiai Kiadó, 2001), 51-93.

55 Piers Vibetsky, "Shamanism", Indigenous Religions: A Companion, ed. Graham Harvey (London: Bloomsbury Publishing, 2000), 55.

56 Pharo, "A Methodology for a Deconstruction and Reconstruction of the Concepts 'Shaman' and 'Shamanism'”, 11. 
bu açıkça bir çeşit indirgemeciliktir. Bu durumda yerel dinleri Şamanizm olarak nitelendirmek onların bireysel kimliklerini ortadan kaldırmaktadır. Alice Back Kehoe'nin "Batılı olmayan tüm küçük toplumların dinlerini "şamanik" olarak adlandırmak, ırkçı bir yaklaşımdır" 57 ifadesi söz konusu yaklaşımın arkasındaki zihinsel bakışı açı etmektedir. Çünkü bu yaklaşım, içerisinde uygar olan/olmayan ve Batılı olan/olmayan ayırımını barındırdığından bu bakış açısının kadim dönem için uygulanması mümkün görünmemektedir. Üstelik günümüzdeki "avc1-toplayıc1" ve "basit" toplumların din mensuplarının kendilerinin "Şamanistik" olarak adlandırılmasını veya sınıflandırmasını kabul edip etmeyeceği de başka bir problem olarak belirmektedir. Sözgelimi Kuzey Amerikalı birçok yerli topluluğun "Şamanistik" olarak anılmayı reddettikleri ve neo-Şamanların uyuşturucu kullanarak Şaman olunacağına dair gerçekle bağdaşmayan hikayeler uydurduklarını öne sürmektedir. ${ }^{58} \mathrm{Bu}$ bağlamda Dowson'ın da belirttiği gibi, mesele Şamanizm'i tanımlama meselesi değildir. Bu sebeple Şamanizm kavramının radikal bir şekilde yeniden değerlendirilmesi gerekmektedir. ${ }^{59}$ Çünkü Şamanizm'in "yerel" kültürleri gerçekten kapsayıp kapsamadığı meselesi ciddi bir problemdir.

\section{Maneviyatın, Sanatın ve Şifacılığın Kökeni Olarak Şamanizm}

Şamanizm, günümüzde artık sadece din ve maneviyat ile ilgili bir kavram olmanın ötesinde birçok alanla ilişkilendirilmektedir. Aslında Şamanizm'in günümüzde popülaritesini sürdürmesindeki temel sebebin de bu çok yönlülük olduğunu söylemek mümkündür. Dolayısıyla Şaman ve Şamanizm bir yandan egzotik bir yabancıyı anımsatırken bir yandan ruhsal şifa uygulamalarını çağrıştırmaktadır. Böylece Şamanizm kültür, sanat, müzik, dans, avcılık, siyaset ve antik dönem gibi birçok fenomenle ilişkilendirilmektedir. Bu durumda "Şaman" kavramı dini liderler, şifacılar, mistikler ve siyasi liderler için kullanılan bir kavram olarak karşımıza çıkmaktadır. ${ }^{60}$ Bilimsel çevrelerde artık şüpheyle yaklaşılan bu görüş uzun bir dönem sanatın ve bir anlamda modern sanatın ilham kaynağı olarak

\footnotetext{
57 Alice Beck Kehoe, Controversies in Archaeology (London: Routledge, 2008), 128.

58 Pharo, "A Methodology for a Deconstruction and Reconstruction of the Concepts 'Shaman' and 'Shamanism'", 13.

59 Thomas A. Dowson, "Re-Animating Hunter-Gatherer Rock-Art Research", Cambridge Archaeological Journal, 19/3 (2009): 379.

60 Winkleman, "Shamanism and the Origins of Spirituality and Ritual Healing", 458-59.
} 
düşünülmüştür. Özellikle Paleolitik döneme tarihlenen mağara resimleri üzerinden Şamanizm ile sanat arasında bir ilişkinin kurulduğunu söylemek mümkündür. Nitekim Winkelman, söz konusu döneme ait mağara resimlerinin ritüel amaçlı yapıldığını ve birçok açıdan Şamanizm'in merkezi özelliklerini taşıdığını ileri sürmektedir. ${ }^{61}$ Campbell ise, insanın ruhundaki tanrısallığ 1 ve görünmeyeni bizim için yorumlayanın yani diğer bir ifadeyle günümüzdeki Şamanlık görevinin sanatçllara geçtiğini düşünmektedir. Ona göre sanatçı yani Şaman mitleri günümüze aktaran kişidir. ${ }^{62}$

Üst Paleolitik döneme ait Lascaux, Altamira ve Chauvet gibi mağaralarda resimlerin keşfedilmesi büyük bir şaşkınlık meydana getirmiştir. Zira "vahşi" ve "ilkel" olarak kodlanan kadim dönem insanının sanatla uğraşacak kadar vaktinin olmadığı öngörülüyordu. Hele hele mağaraların ulaşılması en zor kuytu ve karanlık köşelerinde simgesel gücü yüksek resimlerin çizilmesi ve bu durumun din ile ilişkilendirilmesi ilginç bir durumdu. Çünkü mevcut anlayışa göre dinin ortaya çıkabilmesi için birkaç on bin yılın daha geçmesi gerekiyordu. ${ }^{63}$ Kaya resimleriyle ilgili öne çıkan isimlerden biri olan James D. Lewis-Williams'a göre söz konusu çizimler Şamanın zihin dünyasını yansıtmaktadır. Diğer bir ifadeyle bu resimlerde Şaman'ın zihinsel durumlarını, duygu dünyasını ve ruhsal yolculuğunu karmaşık bir kurgu içerisinde görmekteyiz. ${ }^{64}$ Fakat aradan geçen binlerce yıl boyunca ortaya çıkan medeniyetlerden etkilenmeden Şamanizm'in bugüne "saf" bir şekilde ulaşması mümkün görünmemektedir. Bu durumu kantllayacak herhangi bir veriye sahip değiliz. Dolayısıyla Şamanizm'in evrensel bir kavram olarak öne süren bu yaklaşım sorunlu görünmektedir.

\section{Değerlendirme}

Din bilimleri alanında kullanılan kimi temel kavramlar, Batılı düşünürlerin araştırdıkları toplumlara ait olan yerel terimlerdir. Süreç içerisinde bu kavramlar coğrafyayı ve hatta zamanı aşan geçmiş ve şimdiki inançları ifade etmek üzere kullanılmışlardır. Bu durum Batılı araştırmacıların modern öncesi toplumları anlamak noktasında adeta bir maymuncuk görevi gören kavramlara sahip olduklarını

\footnotetext{
61 Michael Winkelman, “Orijinal Nöroteoloji Olarak Şamanizm”, 81.

62 Campbell, Moyers, Mitolojinin Gücü, 134.

63 James David Lewis-Williams, Mă̆aradaki Zihin, çev.: Tolga Esmer (İstanbul: Yap1 Kredi Yayınları, 2019), 42.

64 Lewis-Williams, Mă̆aradaki Zihin, 123.
} 
düşündürmüştür. Böylece Şamanizm kavramı üzerinde Paleolitik sanatçıları, Sibirya çobanlarını, Çatalhöyük ve Amazon yerlilerini, kısacası dünyanın her yerini anlayabileceklerini öngörmüşlerdir. ${ }^{65}$ Oysa bu kavram her ne kadar genelleyici olması hasebiyle pratik görünse de birçok probleme de sebep olmaktadır. Şamanizm kaya resimlerinden çeşitli objelere varıncaya kadar yapılış ve kullanış sebebi tam olarak anlaşılamayan durumları açıklamak üzere de kullanılmaktadır. Ancak bu durum açıklayıcı olmaktan ziyade özellikle antropoloji, arkeoloji ve dinler tarihi gibi disiplinler açısından muğlak bir alana işaret etmektedir. Şamanizm kavramının süreçsel analizinde de görüldüğü gibi, özellikle Eliade'nin çalışmasından sonra kavram oldukça farklı yönlere doğru evrilmiş ve birçok alanla ilişkilendirilmiştir. Problemin çözümü konusunda Şamanizm kavramından ne anlaşıldığının ortaya konması önem arz etmektedir. Aksi takdirde "doğa" ve "esrime" ile ilişkili her uygulamanın Şamanizm kavramı ile açıklanması Batılı zihnin mirası olan dikotominin sürdürülmesi ve gerçek anlamın bulanıklaştırılması sonucunu ortaya çıkaracaktır.

\section{Kaynakça}

Adıbelli, Ramazan. Mircea Eliade ve Din. İstanbul: İz Yayıncılık, 2011.

Bahn, Peter. "Save the Last Trance for me: An Assessment of the Misuse of Shamanism in Rock Art Studies". The Concept of Shamanism: Uses and Abuses, ed. Robert Hamayon Henri-Paul Francfort, Budapest: Akadémiai Kiadó, 2001, 51-93.

Castaneda, Carlos. Don Juan'ın Öğretileri. Çev. Nevzat Erkmen. İstanbul: Epsilon Yayinevi, 2009.

Campbell, Joseph. Bill Moyers. Mitolojinin Gücü. Çev. Zeynep Yaman. İstanbul: Media Cat, 2013.

Dowson, Thomas A. "Re-Animating Hunter-Gatherer Rock-Art Research". Cambridge Archaeological Journal 19/3 (2009): 378-387.

DuBois, Thomas. "Contemporary Research on Shamanism". Numen, 58 (2011): 100-128.

Eliade, Mircea. Mitler, Rüyalar ve Gizemler. Çev. Cem Soydemir. Ankara: Doğu Batı Yayınları, 2017.

. Şamanizm: İlkel Esrime Teknikleri. Çev. İsmet Birkan. İmge Kitabevi Yayınları, 2014.

Flaherty, Gloria. Shamanism and the Eighteenth Century. Princeton: Princeton University Press, 1992.

Harner, M. Şaman'ın Yolu. Çev. Meral Bolak. İstanbul: Mia Yayınları, 2006.

65 Kehoe, Controversies in Archaeology, 128. 
Hayden, Brian. Shamans, Sorcerers, and Saints: A Prehistory of Religion. Washington: Smithsonian Books, 2003.

Hoppal, Mihaly. "Sibirya Şamanizminde Doğa Tapınımı". Çev. Gürbüz Erginer. Ankara Üniversitesi Dil ve Tarih-Coğrafya Fakültesi Dergisi 41/12 (2017).

Keeney, Bradford. Shamanic Christianity: The Direct Experience of Mystical Communion. Vermont: Destiny Books, 2006.

Kehoe, Alice Beck. Controversies in Archaeology. London: Routledge, 2008.

Levi-Strauss, Claude. Günümüzde Totemizm. Çev. Kasım Akbaş. İstanbul: Nora Yayınları, 2018.

- Yapısal Antropoloji. Çev. Adnan Kahiloğulları. Ankara: İmge Kitabevi Yayınları, 2012.

Lewis-Williams, James David. Mağaradaki Zihin. Çev. Tolga Esmer. İstanbul: Yapı Kredi Yayınları, 2019.

Mille, Richard De. Castaneda's Journey: The Power and the Allegory. Capra Press, 1976.

Noel, Daniel. The Soul of Shamanism: Western Fantasies, Imagined Realities. New York: Continuum International Publishing Group, 1998.

Perrin, Michel. Şamanizm. Çeviren Bülent Arıbaş. İstanbul: İletişim Yayınlar1, 2014.

Pharo, Lars Kirkhusmo. "A Methodology for a Deconstruction and Reconstruction of the Concepts 'Shaman' and 'Shamanism'". Numen 58/1 (2011): 6-70.

Porr, Martin. Hannah Rachel Bell. “'Rock-art', 'Animism' and Two-way Thinking: Towards a Complementary Epistemology in the Understanding of Material Culture and 'Rock-art' of Hunting and Gathering People". Journal of Archaeological Method and Theory 19/1 (2012): 161-205.

Sidky, Homayon. "Ethnographic Perspectives on Differentiating Shamans from other Ritual Intercessors". Asian Ethnology 69/2 (2010): 213-240.

Tylor, E. B. Primitive Culture: Researches into the Development of Mythology, Philosophy, Religion, Language, Art, and Custom. London: 1903.

Vitebsky, Piers. "Shamanism". Indigenous Religions: A Companion, ed. Graham Harvey, London: Bloomsbury Publishing, 2000, 55-67.

Wallis, Robert J. Shamans/Neo-Shamans: Ecstasies, Alternative Archaeologies and Contemporary Pagans. London: Routledge, 2003.

Winkelman, Michael. “Orijinal Nöroteoloji Olarak Şamanizm”. Çev. Ramazan Adıbelli, Erciyes Üniversitesi İlahiyat Fakültesi Dergisi 1/20 (2015): 77-102.

. "Shamanism in Cross-Cultural Perspective". International Journal of Transpersonal Studies 31/2 (2012): 47-62.

. "Shamanism and the Origins of Spirituality and Ritual Healing". Journal for the Study of Religion, Nature and Culture 3/4 (2010): 458-89.

Znamenski, Andrei. The Beauty of the Primitive: Shamanism and Western Imagination. Oxford: Oxford University Press, 2007. 